\title{
Analysis of Damage Rod String Components In Sucker Rod Pump In The Field Ss
}

\author{
Fitrianti ${ }^{1}$, Anwar Haryono ${ }^{2}$ \\ Petroleum Engineering Department, Universitas Islam Riau \\ Jalan Kaharuddin Nst No 113 Marpoyan, Pekanbaru, Indonesia
}

\begin{abstract}
Field SS is a Heavy Oil field which means high viscosity oil making it difficult to flow. Therefore, artificial lift was used in this field to help lifting the high viscosity fluid, ie sucker rod pump (SRP). In the last several year, problem of the damage to the rod string was frequently occur. Rod string damage is usually indicated by the occurrence of broken or detached components. In order to overcome the damage of rod string components on the sucker rod pump, several parameters that causes rod string damage in 41 well samples in the field SS were analytzed and then recommendations was made as an alternative to minimize the occurrence of rod string damage. After analyzing the parameters that can cause rod string damage on 41 well samples in SS field, the cause of the breakdown of rod string is fluid pounding for 37 samples well, while the causes for 4 samples of other wells is not detected. After that, recommendation efforts is done, like size down pump speed and stroke length for 9 samples of wells, size down pump size and pump speed for 6 samples of wells and size down pump speed for 22 samples well. As for the undetected cause 4 samples of wells, is recommended to do proactive well service.
\end{abstract}

Keywords: artificial lift, rod string, fluid pounding, pump speed, stroke length, pump size, well service.

Coresponding author : fitrianti@eng.uir.ac.id

\section{INTRODUCTION}

The production process for obtaining oil, beginning with the fluid flow to the surface naturally due to the high reservoir pressure, therefore it is able to produce as natural flow. As the length of an oil well produces, usually the well can no longer flow the fluid to the surface naturally flow due to the declining reservoir pressure. For that, artificial lift method can be applied to help the production fluid lift to the surface.

Field SS is a Heavy Oil field which means it contains oil with high viscosity (Akkurt, 2005), and ${ }^{\circ}$ API belonging to oil (Rukmana, 2012). So the Field SS is using one artificial lift that can lift fluids with high viscosity levels and ${ }^{\circ} \mathrm{API}$ that is belong to heavy oil, namely the type of sucker rod pump (SRP) or commonly known as the nod pump.

Pumping system consists of four main parts: prime mover, surface unit, rod string and downhole pump. One of the main parts of the rod string is a series of stalks the connecting pipes between the surface equipment and the pump circuit is in the well (downhole pump). In recent years, it often happens problems of damage to the rod string. It is usually indicated with the occurrence of a broken or detached component.

On the SS field problem of rod string breakdown, it is not known definitely yet what causes the damage. Therefore, an analysis of wells is needed which suffered a rod string breakdown in the SS field by performing parameter analysis which can cause rod string breakdown. Once it is

analyzed and knowing the damage cause, then a recommendation is made as an alternative to minimize the occurrence of rod string damage. 


\section{METHODOLOGY}

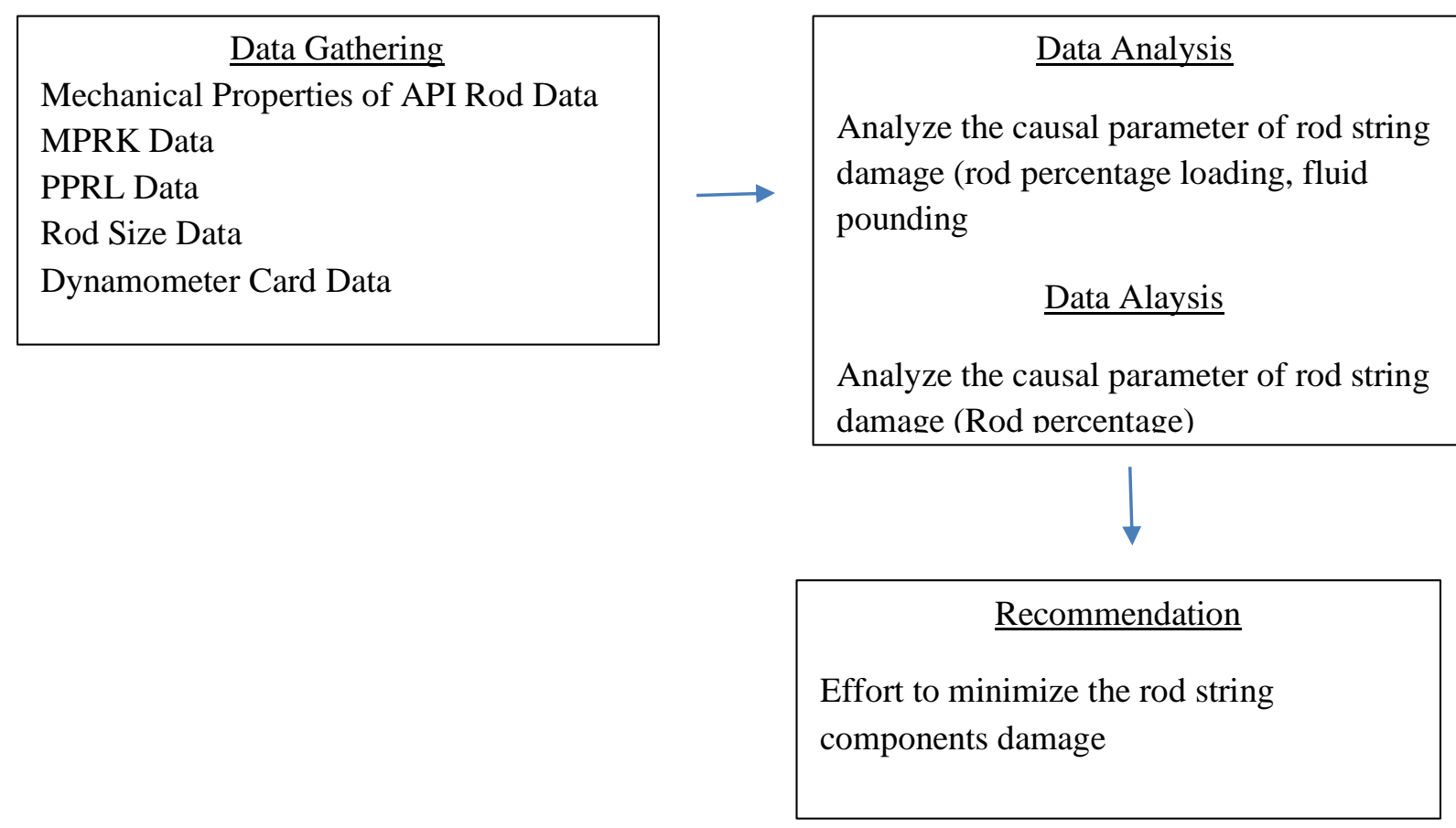

Figure 1 Reaserch Method

\section{ANALYSIS OF CAUSE OF ROD STRING DAMAGE}

\section{Rod Loading}

Data analysis is done to determine whether rod string component has excess load or not, that is by knowing the value of rod load percentage than the load the maximum allowed on the type and size of the rod. The value of the rod loading percentage which is greater than $100 \%$ can indicate that the rod string component is experiencing overloaded.

The analysis is done beginning with the determination of rod loading percentage. Determination of rod percentage loading is done by doing calculations through the Goodman Modification API equation diagram. The result of rod loading percentage determination can be seen in table 1 below:

Tabel 1. Result of Rod Loading Calculation

\begin{tabular}{cccccccc}
\hline No & Well Name & $\begin{array}{c}\text { Rod Area } \\
\text { (in) }\end{array}$ & $\begin{array}{c}\text { Smax } \\
\text { (Psi) }\end{array}$ & $\begin{array}{c}\text { Smin } \\
\text { (Psi) }\end{array}$ & SF & SA (Psi) & $\begin{array}{c}\text { Rod } \\
\text { loading } \\
\text { (\%) }\end{array}$ \\
\hline $\mathbf{1}$ & AH01 & 0.60 & 3158.78 & 1638.05 & 0.8 & 23737.12 & 7 \\
\hline $\mathbf{2}$ & AH02 & 0.44 & 8945.50 & 960 & 0.8 & 23432 & 36 \\
\hline $\mathbf{3}$ & AH03 & 0.60 & 4939.47 & 1302.69 & 0.8 & 23586.21 & 16 \\
\hline $\mathbf{4}$ & AH04 & 0.78 & 4236.75 & 410.87 & 0.8 & 23184.89 & 17 \\
\hline $\mathbf{5}$ & AH05 & 0.61 & 7907.71 & 552.84 & 0.8 & 23248.78 & 32 \\
\hline $\mathbf{6}$ & AH06 & 0.60 & 5303.58 & 754.04 & 0.8 & 23339.32 & 20 \\
\hline $\mathbf{7}$ & AH07 & 0.60 & 6026.57 & 814.66 & 0.8 & 23366.6 & 23 \\
\hline $\mathbf{8}$ & AH08 & 0.78 & 8128.36 & 4416 & 0.8 & 24987.2 & 18 \\
\hline
\end{tabular}


Fitrianti, Anwar Haryono /JEEE Vol. 07 No. 01/2018

\begin{tabular}{cccccccc}
\hline $\mathbf{9}$ & AH09 & 0.60 & 4627.03 & 1400.51 & 0.8 & 23630.23 & 15 \\
\hline $\mathbf{1 0}$ & AH10 & 0.60 & 4618.38 & 1035.83 & 0.8 & 23466.12 & 16 \\
\hline $\mathbf{1 1}$ & AH11 & 0.60 & 5560.99 & 1018.07 & 0.8 & 23458.13 & 20 \\
\hline $\mathbf{1 2}$ & AH12 & 0.60 & 5305.23 & 1983.92 & 0.8 & 23892.76 & 15 \\
\hline $\mathbf{1 3}$ & AH13 & 0.44 & 9235.23 & 1427 & 0.8 & 23662.4 & 35 \\
\hline $\mathbf{1 4}$ & AH14 & 0.44 & 7863.96 & 1062.09 & 0.8 & 23477.94 & 30 \\
\hline $\mathbf{1 5}$ & AH15 & 0.60 & 5006.15 & 728.88 & 0.8 & 23328 & 19 \\
\hline $\mathbf{1 6}$ & AH16 & 0.60 & 7859.82 & 588.88 & 0.8 & 23264.99 & 32 \\
\hline $\mathbf{1 7}$ & AH17 & 0.60 & 6381.23 & 184.76 & 0.8 & 23083.14 & 27 \\
\hline $\mathbf{1 8}$ & AH18 & 0.60 & 4751.44 & 1112.35 & 0.8 & 23500.56 & 16 \\
\hline $\mathbf{1 9}$ & AH19 & 0.78 & 4602.11 & 1233.54 & 0.8 & 23555.09 & 15 \\
\hline $\mathbf{2 0}$ & AH20 & 0.61 & 9628.22 & 2527.27 & 0.8 & 24137.27 & 33 \\
\hline $\mathbf{2 1}$ & AH21 & 0.61 & 4845.62 & 986.53 & 0.8 & 23443.94 & 17 \\
\hline $\mathbf{2 2}$ & AH22 & 0.44 & 5108.39 & 1821.98 & 0.8 & 23819.89 & 15 \\
\hline $\mathbf{2 3}$ & AH23 & 0.60 & 3795.16 & 1534.53 & 0.8 & 23690.54 & 10 \\
\hline $\mathbf{2 4}$ & AH24 & 0.60 & 3804.96 & 950.86 & 0.8 & 23427.89 & 13 \\
\hline $\mathbf{2 5}$ & AH25 & 0.78 & 3101.09 & 998.12 & 0.8 & 23449.26 & 9 \\
\hline $\mathbf{2 6}$ & AH26 & 0.44 & 5246.04 & 1319.34 & 0.8 & 23593.7 & 18 \\
\hline $\mathbf{2 7}$ & AH27 & 0.44 & 8366.03 & 746.67 & 0.8 & 23336 & 34 \\
\hline $\mathbf{2 8}$ & AH28 & 0.44 & 5684.92 & 1326.91 & 0.8 & 23597.11 & 20 \\
\hline $\mathbf{2 9}$ & AH29 & 0.60 & 3459.05 & 1188.57 & 0.8 & 23534.86 & 10 \\
\hline $\mathbf{3 0}$ & AH30 & 0.60 & 6529.55 & 536.65 & 0.8 & 23241.49 & 26 \\
\hline $\mathbf{3 1}$ & AH31 & 0.60 & 5575.07 & 998.09 & 0.8 & 23449.14 & 20 \\
\hline $\mathbf{3 2}$ & AH32 & 0.78 & 3751.62 & 835.40 & 0.8 & 23375.93 & 13 \\
\hline $\mathbf{3 3}$ & AH33 & 0.44 & 7488.27 & 950.57 & 0.8 & 23427.76 & 29 \\
\hline $\mathbf{3 4}$ & AH34 & 0.44 & 7648.08 & 870.98 & 0.8 & 23391.94 & 30 \\
\hline $\mathbf{3 5}$ & AH35 & 0.60 & 23084.16 & 11593.95 & 0.8 & 28217.28 & 69 \\
\hline $\mathbf{3 6}$ & AH36 & 0.60 & 5102.97 & 1247.80 & 0.8 & 23561.51 & 17 \\
\hline $\mathbf{3 7}$ & AH37 & 0.60 & 3677.03 & 931.54 & 0.8 & 23419.20 & 12 \\
\hline $\mathbf{3 8}$ & AH38 & 0.44 & 4124.34 & 1691.84 & 0.8 & 23761.33 & 11 \\
\hline $\mathbf{3 9}$ & AH39 & 0.44 & 7488.27 & 950.57 & 0.8 & 23427.76 & 29 \\
\hline $\mathbf{4 0}$ & AH40 & 0.60 & 30279.25 & 16507.53 & 0.8 & 30428.39 & 99 \\
\hline $\mathbf{4 1}$ & AH41 & 0.60 & 3631.99 & 1805.25 & 0.8 & 23812.36 & 8 \\
\hline & & & & & & & \\
\hline
\end{tabular}

From the table table $4.1 \mathrm{It}$ is seen that the percentage value of rod loading on each well is less than $100 \%$. This means that the loading received against the rod string component is still in safe condition and show that rod loading percentage is not the cause for damage to rod string components. 


\section{Fluid Pounding}

Fluid pounding analysis is done by finding out the amount of pump fillage value obtained in each SRP. The value of pump fillage $<90 \%$ has a tendency to result the occurrence of fluid pounding that led to the occurrence of damage to the rod string component.

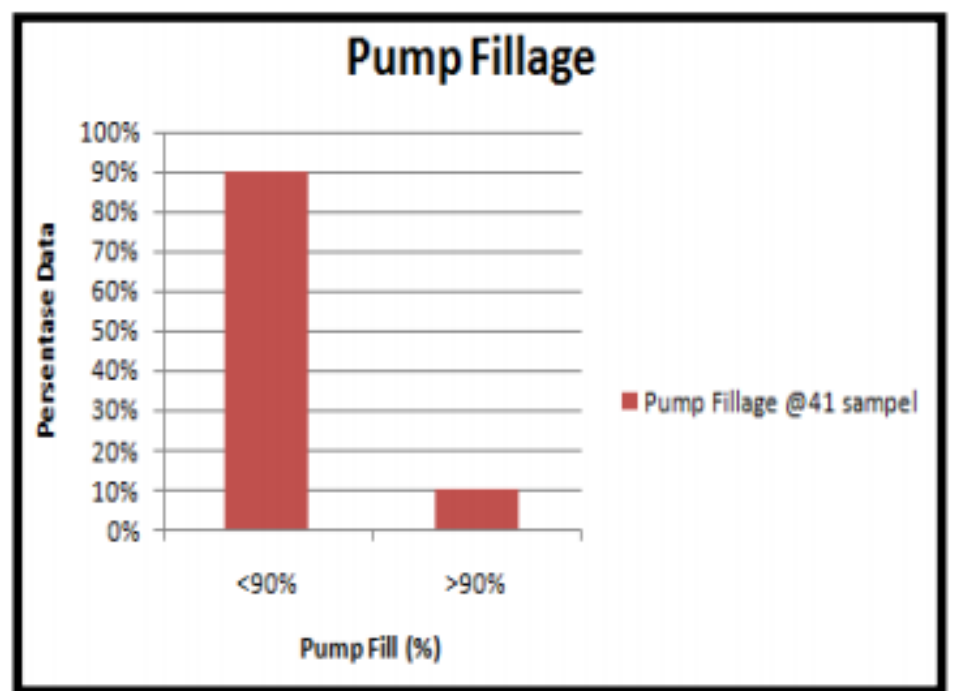

Figure 1.2 Graph data Pump fillage for 41 Wells

In Figure 4.2, it is seen that pump fillage value $<90 \%$ has greater frequency compared with pump fillage value $>90 \%$. It shows that fluid pounding has a tendency to cause damage to the rod string component. Based on the results in Figure 4.2 the percentage of data for the pump fillage value $<90 \%$ by $90 \%$ and percentage of data for pump fillage value $>90 \%$ by $10 \%$. It shows that if accumulated with a total of 41 well samples studied, then there are 37 well samples with pump fillage value $<90 \%$ and 4 sample wells with pump fillage value> $90 \%$. Through the result, it can be seen that 37 samples of wells that suffered damage rod string tends to be caused by fluid pounding problems due to not optimal pump fillage on the well.

\section{Interpretation of Dynamometer Data}

Based on the analysis of fluid ponding, there are 4 wells that have been damaged at component rod string, but it is not known what the cause of the component malfunction. Therefore, the interpretation of the dynamometer data to find out other problems which is received by 4 wells that make it unindicable cause of rod string breakdown.

Analysis of the data performed, is looking at the value of pump slip from the 4 samples of the well. The tolerable limit of pump slip on a pump is $<9 \%$. If the value pump slip to 4 wells above $9 \%$, then it can be indicated very severe leaks in standing or traveling valve. For data interpretation results dynamometer, can be seen in table 1

\begin{tabular}{cccl}
\hline No & Well Name & $\begin{array}{c}\text { Pslip } \\
(\boldsymbol{\%})\end{array}$ & \multicolumn{1}{c}{ Statement } \\
\hline $\mathbf{1}$ & AH19 & 10 & Downhole pump leak indicated \\
\hline $\mathbf{2}$ & AH22 & 24 & Downhole pump leak indicated \\
\hline $\mathbf{3}$ & AH29 & 36 & Downhole pump leak indicated \\
\hline $\mathbf{4}$ & AH37 & 19 & Downhole pump leak indicated \\
\hline
\end{tabular}




\section{EFFORTS OF MINIMIZING ROD STRING DAMAGES}

Data processing in the form of calculations performed to provide appropriate recommendations to the problems that occur. Recommendations given, according to some provisions stipulated by the company in the form of:

a. Available pump size is size (3.75 ", 2.75", 2.25 "and 1.75")

b. Type of pump available (BKKC114-119-100 / 01 / CW with its pump stroke value ie 100 in, 86 in, 69 in and LFKC228-185-144 / 01 / CW with pump stroke value that is 144 in, 124 in, 104 in)

c. Optimal Pump fillage (PF) determination is $90 \%$

Based on this, calculations are made to obtain the capacity design optimal pump. Recommendations made can be Size down pump speed, size down stroke length, size down pump size or a combination of all three.

\section{Determination for Size Down Pump Stroke (Sp) and Pump Speed (N)}

The recommendation determination for Size Down Pump Speed (N) and Pump stroke (Sp) is done by calculating the value of new pump capacity (PD), then looking for pump speed which is used as a recommendation by assuming a new stroke length to meet the optimum pump fillage criteria of $90 \%$. Result of recommendation determination for size down pump speed $(\mathrm{N})$ and stroke length $(\mathrm{Sp})$ can be seen in table 3 as follows:

Table 3 The Results of Size Down Pump Stroke and Size Down Pump Speed

\begin{tabular}{cccccccc}
\hline No & Well & \multicolumn{2}{c}{ PF (bfpd) } & \multicolumn{2}{c}{ Pump Stroke (in) } & \multicolumn{2}{c}{ Pump speed (SPM) } \\
\cline { 3 - 8 } & Name & Initial & New & Initial & New & Initial & New \\
\hline $\mathbf{1}$ & AH2 & 758 & 388 & 100 & 86 & 8.6 & 6 \\
\hline $\mathbf{2}$ & AH3 & 845 & 447 & 101 & 69 & 9.5 & 6 \\
\hline $\mathbf{3}$ & AH7 & 918 & 296 & 104.23 & 86 & 10 & 7 \\
\hline $\mathbf{4}$ & AH16 & 727 & 386 & 99.5 & 69 & 8.3 & 6 \\
\hline $\mathbf{5}$ & AH20 & 1548 & 750 & 100 & 69 & 9.4 & 7 \\
\hline $\mathbf{6}$ & AH26 & 336 & 161 & 100.24 & 69 & 9.4 & 7 \\
\hline $\mathbf{7}$ & AH33 & 1377 & 969 & 100.09 & 86 & 8 & 7 \\
\hline $\mathbf{8}$ & AH34 & 1086 & 338 & 100.23 & 69 & 12.3 & 6 \\
\hline $\mathbf{9}$ & AH39 & 1316 & 625 & 145 & 124 & 10.3 & 6 \\
\hline
\end{tabular}

\section{Determination for Size Down Pump Size (D) and Pump Speed (N)}

The recommendation determination for Size Down Pump Speed (N) and Pump stroke (Sp) is done by calculating the value of new pump capacity (PD), then looking for pump speed 6 which is used as a recommendation by assuming a new stroke length to meet the optimum pump fillage criteria of $90 \%$. The recommendation results of size down pump speed $(\mathrm{N})$ and stroke length $(\mathrm{Sp})$ were showed in Table 4 as follows

Table 4 The Results of Size Down Pump Size and Size Down Pump Speed

\begin{tabular}{llllllll}
\hline \multirow{2}{*}{ No } & Well & \multicolumn{2}{l}{ PD (BFPD) } & \multicolumn{2}{c}{ Pump Size (in) } & \multicolumn{2}{c}{ Pump speed (SPM) } \\
\cline { 3 - 8 } & & Initial & New & Initial & New & Initial & New \\
\hline $\mathbf{1}$ & AH9 & 768 & 213 & 2.75 & 1.75 & 8.6 & 6 \\
\hline $\mathbf{2}$ & AH10 & 784 & 392 & 2.75 & 2.25 & 8.9 & 7 \\
\hline $\mathbf{3}$ & AH14 & 1065 & 260 & 2.75 & 1.75 & 12.1 & 7 \\
\hline $\mathbf{4}$ & AH18 & 984 & 415 & 2.75 & 2.25 & 9 & 6 \\
\hline $\mathbf{5}$ & AH21 & 567 & 157 & 2.75 & 1.75 & 9.4 & 6 \\
\hline $\mathbf{6}$ & AH31 & 892 & 290 & 2.75 & 1.75 & 10.1 & 8 \\
\hline
\end{tabular}




\section{Calculation for Size Down Pump Speed (N)}

Determination to Size Down Pump Speed (N) is conducted using calculation of new value of pump capacity, then measure the new pump speed that used as recommendation to fulfill criteria of pump fillage optimum, that is $90 \%$. The recommendation results of size down pump speed $(\mathrm{N})$ and stroke length (Sp) were explained in Table 5 as follows

Table 5 The Results of Size Down Pump Speed

\begin{tabular}{llllll}
\hline No & Well & PD (BFPD) & \multicolumn{2}{l}{ Pump Speed (SPM) } \\
\cline { 4 - 6 } & & Initial & New & Initial & New \\
\hline $\mathbf{1}$ & AH1 & 503 & 292 & 8.1 & 6 \\
$\mathbf{2}$ & AH4 & 2234 & 1848 & 9.4 & 8 \\
\hline $\mathbf{3}$ & AH5 & 991 & 696 & 9 & 6 \\
\hline $\mathbf{4}$ & AH6 & 2601 & 2189 & 11.0 & 9 \\
\hline $\mathbf{5}$ & AH8 & 1178 & 769 & 10 & 7 \\
\hline $\mathbf{6}$ & AH11 & 1492 & 1234 & 9.1 & 8 \\
\hline $\mathbf{7}$ & AH12 & 581 & 329 & 9.7 & 6 \\
\hline $\mathbf{8}$ & AH13 & 998 & 815 & 11.8 & 10 \\
\hline $\mathbf{9}$ & AH15 & 2028 & 1707 & 12.3 & 10 \\
\hline $\mathbf{1 0}$ & AH17 & 2572 & 2159 & 10.9 & 9 \\
\hline $\mathbf{1 1}$ & AH23 & 1077 & 934 & 12.2 & 9 \\
\hline $\mathbf{1 2}$ & AH24 & 1745 & 1425 & 7.4 & 6 \\
\hline $\mathbf{1 3}$ & AH25 & 1066 & 880 & 8.4 & 7 \\
\hline $\mathbf{1 4}$ & AH27 & 595 & 508 & 7 & 6 \\
\hline $\mathbf{1 5}$ & AH28 & 402 & 320 & 11.1 & 9 \\
\hline $\mathbf{1 6}$ & AH30 & 335 & 265 & 9.4 & 7 \\
\hline $\mathbf{1 7}$ & AH32 & 1932 & 1591 & 11.7 & 10 \\
\hline $\mathbf{1 8}$ & AH35 & 894 & 724 & 10.2 & 8.3 \\
\hline $\mathbf{1 9}$ & AH36 & 423 & 350 & 8.3 & 7 \\
\hline $\mathbf{2 0}$ & AH38 & 598 & 485 & 9.7 & 8 \\
\hline $\mathbf{2 1}$ & AH40 & 863 & 661 & 9.5 & 7.3 \\
\hline $\mathbf{2 2}$ & AH41 & 707 & 581 & 7.7 & 6.3 \\
\hline & & & & & \\
\hline
\end{tabular}

There are four (4) sample's wells that have been damaged in rod string. However, no indications of damage factor. This matter should conduct recommendation that is proactive well service. It is used to indicates the presence of leakage. These data can be seen on Table 6

Table 6 Recommendation Results to 4 wells that indicates pump leak

\begin{tabular}{llll}
\hline No & Well & Pslip (\%) & Description \\
\hline $\mathbf{1}$ & AH19 & 10 & It should be conducted the process of proactive well service \\
\hline $\mathbf{2}$ & AH22 & 24 & It should be conducted the process of proactive well service \\
\hline $\mathbf{3}$ & AH29 & 36 & It should be conducted the process of proactive well service \\
\hline $\mathbf{4}$ & AH37 & 19 & It should be conducted the process of proactive well service \\
\hline
\end{tabular}

\section{CONCLUSION}

Based on analysis of parameter that causing damage in rod string, it can conclude that :

1. Based on the analysis to the obtained data, the due factor of damage in rod string component is fluid ponding. It is for 37 wells. In other hand, 4 wells indicates pump damage that caused by leakage in down hole pump component.

2. The recommendations of 37 wells that have been damaged in rod string are size down of stroke length, 9 wells is recommended to pump speed. Meanwhile, 22 wells to size down pump speed, 6 
wells to size down pump size and pumping speed. And for the rest, these wells should conduct proactive well service.

\section{REFERENCES}

Akkurt, R. (2005). Ranking Oil Viscosity in Heavy Oil Reservoir. SPWLA

Brown, K.E. (1980). The Technology of Artificial Lift Methods. Volume 2A Petroleum Publishing Company. Tulsa Oklahoma.

Ehimeakha, V. (2005). Calculating Pump Fillage For Well Control Using Transfer Point Location. SPE

Festini. D (2007). Beam Pumping System Optimization Trough Automation. SPE

Hermanson, D. E. (1987). Petroleum Engineering Handbook. Ltv Energy Products.

Mustafa, M.G (2017). Performance Evaluation of the Different Sucker Rod Artificial Lift Systems. SPE

PT. Chevron Pacific Indonesia. (2016). Rod Pumping Optimization Training, Ulimited Petroleum Consulting. lnc.

Quttainah, R. (2015). Sucker Rod Pump Design Modification to Avoid Pump Floating Phenomena in Heavy-Oil, Low API Wells to Enhance the Production Rate. SPE

Rowlan, O.L. (2003). How to Maintain High Producing Efficiency in Sucker Rod Lift Operation. SPE

Rukmana, D., dkk. (2012). Teknik Reservoir. Pohon Cahaya, Yogyakarta 


\section{NOMENCLATURE}

PD : Pump displacement, BFPD

NPD : Net pump displacement, BFPD

D : Diameter, in

Sp : Stroke length, in

$\mathrm{N} \quad$ : Pump speed, SPM

PF : Pump fillage, $\%$

Pslip : Pump slip, \%

SA : Maximum tension that allowed to rod, psi

$\mathrm{S} \max$ : Maximum tension that accepted by rod, psi

$\mathrm{S}$ min : Minimum tension that accepted by rod, psi

SF : Safety Factor

\section{ATTACHMENTS}

Rod Loading Calculation (AH02)

Data :PPR = $3952 \mathrm{lbs}$

$$
\begin{array}{ll}
\mathrm{MPRL} & =720 \mathrm{lbs} \\
\mathrm{D}_{\mathrm{r}} & =0.75 \mathrm{in} \\
\mathrm{SF} & =0.8 \\
\mathrm{~T} & =115000 \text { psi }(\text { from Table } 2) \\
\text { Calculate } & \% \text { Rod loading }
\end{array}
$$

Solution:

$$
\begin{array}{ll}
\mathrm{A}_{\mathrm{r}} & =\frac{\pi}{4} \times 0.75^{2} \\
& =0.601 \mathrm{in}^{2} \\
\mathrm{~S}_{\max } & =\frac{3952}{0.601} \\
& =8945.5 \mathrm{psi} \\
& =\frac{720}{0.601} \\
\mathrm{~S}_{\min } & =960 \mathrm{psi} \\
& =[(0.25 \mathrm{x} 115000)+(0.562 \times 960)] \times 0.8 \\
\mathrm{SA} & =23432 \mathrm{psi} \\
\% \operatorname{Rod} \operatorname{Load}=\left[\frac{8945.5-960}{23432-960} \times 100\right] & =36 \%
\end{array}
$$

Size Down Pump Speed (N) and Pump Stroke (Sp) Calculation (AH02)

\section{Data : NPD}

Sp (assumption)

PF (assumption)

Pslip

Solution:

Calculate the new PD

$$
\begin{aligned}
\mathrm{PD} \quad & =\frac{N P D}{[P F-P s l i p] / 100} \\
& =\frac{338}{[(90-3) / 100]} \\
& =388 \mathrm{BFPD}
\end{aligned}
$$

Calculate the appropriate speed pump

$$
=338 \text { BFPD }
$$$$
=86 \text { " }
$$$$
=90 \%
$$$$
=3 \%
$$ 
$\mathrm{N}$

$$
\begin{aligned}
& =\frac{P D}{\left[0.1165 \times S p \times D^{2}\right]} \\
& =\frac{388}{\left[0.1165 \times 86 \times 2.75^{2}\right]} \\
& =6 \mathrm{SPM}
\end{aligned}
$$

Size Down Pump Size (D) and Pump Speed (N) Calculation (AH18)

Data : Net displacement $=334$ BPD

$$
\begin{array}{ll}
\mathrm{N} \text { (assumption) } & =6 \mathrm{SPM} \\
\mathrm{PF}(\text { assumption }) & =90 \% \\
\mathrm{P} \text { slip } & =7
\end{array}
$$

Solution:

Calculate the gross displacement

$$
\begin{aligned}
\mathrm{PD} & =\frac{N P D}{[P F-P s l i p] / 100} \\
& =\frac{334}{[(80-7) / 100]} \\
& =472 \mathrm{BFPD}
\end{aligned}
$$

Calculate the appropriate pump size

$$
\begin{aligned}
\mathrm{D} & =\sqrt{\frac{P D}{\left[0.1165 \times S P X D^{2}\right.}} \\
& =\sqrt{\frac{472}{0.1165 \times 6 \times 124}} \\
& =2.25 \mathrm{in}
\end{aligned}
$$

Size Down Pump Speed (N) Calculation (AH05)

$\begin{aligned} \text { Data : Net displacement } & =344 \text { BPD } \\ \text { Sp } & =124.99 " \\ \text { D } & =2.75 \\ \text { PF (assumption) } & =90 \% \\ \text { Pslip } & =7 \%\end{aligned}$

Solution:

$$
\begin{aligned}
& \text { Net displacement } \quad=344 \text { BPD } \\
& \mathrm{D} \quad=2.75 \\
& \begin{array}{ll}
\mathrm{PF} \text { (assumption) } & =90 \% \\
\text { Pslip } & =7 \%
\end{array}
\end{aligned}
$$

Calculate gross displacement

$$
\begin{aligned}
& \text { PD }=\frac{N P D}{[P F-P s l i p] / 100} \\
&= \frac{334}{[(80-6) / 100]} \\
&=696 \mathrm{BFPD}
\end{aligned}
$$

Calculate the appropriate speed pump

$$
\begin{aligned}
\mathrm{N}=\frac{P D}{\left[0.1165 \times S p \times D^{2}\right]} \\
=\frac{696}{\left[0.1165 \times 124.99 \times 2.75^{2}\right]} \\
=6 \mathrm{SPM}
\end{aligned}
$$

